\title{
The Interdependence of Society, Environment and Health and Its Relevance for Societal Development
}

\author{
Ulrich LAASER ${ }^{1}$
}

\begin{abstract}
The relationship between society, environment, and health is governed by values that relate to targets as well as to the process leading there. Health scientists have to obey these universal rules and regulations on how to promote change. Given limited resources, scientists have also to calculate cost and benefit but it is the state to ensure the fundamental human right to live a healthy life under suitable conditions. Taking into account the "Preventive Paradoxon" introduced by Geoffrey Rose and the mandate for public health accredited to the European Commission in the Maastricht Treaty on European Union, progress is to be achieved bottom-up and topdown. Science can help to find the right balance through careful analysis and monitoring but this is no longer a medical domain on its own; it is linked to all societal sectors. The structure to investigate this field is the modern School of Public Health, attached to universities and reaching out to relevant institutions. Four deficits have to be overcome, the information deficit as well as the social deficit, the preventive deficit, and the regulatory deficit. Training for research and serving the health of populations is a mission well worth the effort. The One Health concept offers a unique current framework. For the development of health, it is vital to learn from each other in the belief that health and knowledge know no barriers.
\end{abstract}

Keywords; public health, health sciences, code of ethics, value system, society, environment, health system deficits, Germany

1 Prof. Dr. med., DTM\&H, MPH, University of Bielefeld, School of Public Health, POB 1001 31,D33501Bielefeld,Email: ulrich.laaser@uni-bielefeld.de

DOI:10.17932/EJOH.2020.022/ejoh_v01i1001 
Surah 107 reads:

Hast thou observed? He who denieth the religion,

that is he who repelleth the orphan,

and urgeth not the feeding of the needy.

So, woe unto those who are praying,

who are heedless of their prayer,

those who would be seen,

but withhold the goods.

Surah 107 (1) in its first and older section, likely written down before the Hijra, explains to us the role an accepted religion, or in a wider sense an accepted value-system, has for the organization of society; and in the latter part of the Surah, from after the Hijra, Prophet Mohammed (PBUH) points to the fact that those central values may not only formally be accepted, but have to be truly believed. Thus only values which are convincing to everybody, or at least to a large majority, can fulfil this function in a society and it is interesting to note that as to the content of the core values, at least as far as Surah 107 is concerned, its demands come very close to the Sermon on the Mount of the New Testament.

Quite certainly, it is not common to begin from this angle as religious or ethical aspects usually are taken into account only marginally, or not at all, in a world which cries increasingly for precise figures and sharp analysis. But when we argue for a comprehensive view on the three dimensions of society, environment, and health, we will find that their relationship is governed by values, at least implicitly, whether we like it or not.

\section{The Value System}

Here we may differentiate between values which relate to objectives or targets in content areas as, for example, to enhance the quality of life or to achieve "Health for All" as the World Health Organization expresses and reiterates it in the Millennium Development Goals (2) and the Sustainable Development Goals (3). The other category of values might be called values which describe the process in order to achieve those objectives, i.e. not the "What?" but the "How?" is of interest here. The pure existence of process values as separate from outcome values contradicts the saying that success justifies the means. For us as human beings and members of our societies the ethical consensus on how we want to achieve certain objectives may be 
even more relevant than the outcome. As scientists, however, we usually are much more interested in the effects of interventions, at least we are asked to be as society expects solutions from us for the many problems burdening the people not l'art pour l'art.

To elaborate on the introductory part of Surah 107 (1) observations are reported here. In our time we see observation as an instrumented process which comprises the perception of facts and their identification based on prior experience. No longer do we live, however, in a world where observation is that of an unchangeable nature and, therefore, be naive and without questioning the observed reality. On the contrary, there is nothing in our world which we do not evaluate in terms of good and bad, to be preserved or to be changed. In all civilized, as opposed to a few remaining natural in fact tribal societies, there is a dominance of change over preservation which is signified by the globally positive connotation of the term "development". This is not a so-called Western value but has become a universal one. If so, what are the criteria for the dominating processes of change? The most interesting quality of these criteria is that they cannot be derived. They are axiomatic in the sense of a declaration of belief or of will. They have to be set. The renunciation of violence, for example, is a vital requirement for the functioning of a society. Broad participation of people in the decision making process is a precondition for full exploitation of intellectuality and creativity in a society and, based on this, for its global competitiveness. The Wall in Berlin was brought down through the slogan "Wir sind das Volk" (We are the people!) without any violence, but with an air of extreme happiness. The government, almost two months later, did not even think of unification when the citizens changed the wall breaking slogan into "We are one people". However admittedly, this was the first successful but unbloodied revolution in German history (4).

Most of the process values of today can be tracked down to the three sets of principles of the French revolution: Liberté, Egalité, Fraternité. That is, we are determined to pursue our goals without domination and manipulation and we urge actively not equity but equal opportunities for everybody and we insist that basic needs will be taken care of in our communities predominantly as empowerment for a decent life. If we all could agree globally to these values, or at least those of us around the Mediterranean Sea, the famous "Clash of Cultures" could be transformed into a positive effort for development. Maybe then we would not have seen the violent conflicts, wherever the Christian and the Islamic world overlap: Bosnia, Cyprus, and Lebanon. 
Health scientists should - like everybody - obey these universal rules and regulations on how to promote change. Their domain, however, is to analyse and reflect the direction, the means, and the resulting changes. Here utilitarian ethics $(5,6)$ can almost declare victory as world-wide cost benefit thinking has gained ground. Is that economic dimension of thinking ethical at all? Not if there were unlimited resources! However, that clearly is not the case. In a situation where our means are restricted, every spending for less beneficial purposes, is to the disadvantage of at least some people, whose status could have been improved. The largest benefit, to the greatest possible number is the yardstick and, therefore, the most efficient use of money is mandatory. Squandering resources is unethical! According to the analysis of the Cochrane Centres, up to one third of medical procedures are ineffective or even inefficacious, i.e. not evidence based. On the other hand, even with efficient schemes in the area of clinical care, what is their relative efficiency as compared to other contributions to fulfilment in human life? And what is considered to be fulfilment? It is obvious that these preferences are culturally determined depending on historical, geographical, and traditional factors. Thus, the results of decision making processes are different according to culturally determined priorities set in a league table of measures, ranking quality adjusted years of life saved. The ranking depends on the specific valuation of benefits and involved costs, i.e. on the people's "Willingness to pay" how much for what in a specific society. This setting of priorities according to criteria of efficiency is of immediate relevance to the kind of decisions to be taken by a government. However, governments do not always like the transparency of choices, which are made explicit by a calculation of benefits and costs. To its fullest, this approach is linked to an open society. Nevertheless, all administrations in our time have to observe, along these principles, the three dimensions taken up here: Society, environment, health, and the way they interact.

\section{Society}

What constitutes a society? In most simple terms it is a coherently organized population on a defined territory and, if it is politically autonomous, we call it a state. However, the latter quality is not essential as, for example, Germany was not a state between 1803 and 1871, but there was a feeling of national commonalities expressed in the term of the "Kulturnation" which referred to common cultural characteristics like a German literature. Certainly the Palestinians constitute a society in that sense as they lack most 
of the qualities of an independent state: they are not coherently organized, their territory is not defined and the Palestinian Authority has only limited powers. Nevertheless, nobody hesitates to consider the Germans in the 19th century or the Palestinians today a distinct population, a society or even a nation.

The late Geoffrey Rose, Professor of Epidemiology at the London School of Hygiene and Tropical Medicine developed the argument that the health of a population is not the result of a simple addition of individual biographies, but is determined by indivisible dynamics of its own. In his paper on "Relative Merits of Intervening on Whole Populations Versus High-Risk Individuals Only" (7) he remarks with reference to his own Whitehall data: "It then transpires that most of these deaths do not arise in the clinical part of the range, where risks are high but numbers are few; most arise at lower levels, where the risk to an individual is small but the numbers are large." This is the formula of the "Preventive Paradoxon" considered by many to be Geoffrey Rose's greatest idea. Later-on he coined also the term "Population strategy": Causes of incidence are identified and in consequence modified, whereas the high risk individuals are diagnosed and treated. From the Intersalt data (8), it can be shown that the correlation between mean and prevalence for not only physical, but also for behavioural variables is extremely high in 32 different national settings with a wide spectrum of levels of blood pressure, body mass, alcohol intake and sodium intake. Theoretically the shape of the distribution could change, e.g. by therapy for the high risk group which would cause the prevalence to be independent of the mean. But that is not so, in Geoffrey Rose's words in one of his last papers, (9) on "The population mean predicts the number of deviant individuals"): "Traditional preventive strategy is concerned with identifying and helping minorities with special problems, by treating their risk factors or seeking changes in their behaviour. The underlying aim is to truncate the risk distribution, eliminating the tail but not interfering with the rest of the population. In practice such truncation proves hard or impossible to achieve..., the spread of a distribution is not readily compressed. The close link between mean and prevalence implies, that to help the minority the "normal" majority must change... The health of society is integral".

In a historical period of growing external globalization bringing together persons, ideas and experiences, at the same time, we can observe a process of internal disintegration within our societies, i.e. between: 
- the rich(er) and the poor(er): Social disintegration,

- the young(er) and the old(er): Intergenerational disintegration,

- the (since longer established) natives and the (more recent) immigrants: Cultural disintegration.

It has been demonstrated in European societies that in spite of generally improving life expectancy, some lower social status groups may not only lag behind, but even they may worsen. What is the reason? More frequent exposures to high risks, less access to medical and other services, unhealthy behaviours? The composition of factors could be different for each of those disadvantaged groups. But at least in theory we would not accept unequal chances for health!

For decades e.g. in Germany, there was an unquestioned contract between the generations in that the younger working ages would pay the living of the old. The demographic dynamics and the exploding and costly technical options at the end of life have undermined this arrangement. Germany, therefore introduced an additional obligatory insurance for nursing care. It was an annoying long-lasting battle between the various lobbies who had to pay. But at least in theory one would not accept unequal chances for health!

Migration should be welcome in Europe as a means for growing together but to the contrary there is exclusion and ghettoization. Even in countries with much lower immigration rates than for Germany, xenophobic reactions can be observed. We should consider the provision of specially tailored health care as a means of integration: language problems, differing health beliefs and specific health problems are to be taken care of. Since the last decades Germany is confronted with elderly migrants from the first migration wave in the fifties - mainly from Turkey - left alone by their disintegrating families and unable of going home to their native countries. At the same time there is the experience of a different new immigration wave from the East of Europe. But at least in theory, one would not accept unequal chances for health!

If the population according to Rose reacts as a whole, the role of the state in intervention has to be reconsidered. To refer to a German Jewish physician Salomon Neumann (10) who lived towards the end of the 19th century in Berlin: He created one of the first health insurances for workers leading later-on to Bismarck's Social Insurance Legislation of 1883. Neumann's main postulates concerned the obligation of the state to organize public 
health care and to protect the health of its people. The state should ensure the basic human right to live a healthy life under suitable conditions, improve care for the poor, establish health offices at all administrative levels, organize free medical associations, provide medical statistics of the causes and effects of disease, and last, but certainly not least, let the people participate in its administration. This reference may give an idea how old and long established these concepts are. It is interesting to note that the first step to develop a European health policy has been the mandate for public health accredited to the European Commission in Article 129 of the Maastricht Treaty on European Union (11): "The Community shall contribute towards ensuring a high level of human health protection by encouraging cooperation between Member States and, if necessary, lending support to their action. Community action shall be directed towards the prevention of diseases, in particular the major health scourges, including drug dependence, by promoting research into their causes and their transmission, as well as health information and education. Health protection requirements shall form a constituent part of the Community's other policies".

\section{Environment}

However, modern governments have not to take care of present problems alone but of the survival of the future generations too. The sustainability of their policies is at stake, and, as much as this is a global problem, we have passed already the historical period of national governments and now witness the emergence of world politics. There is an obvious interrelationship between society and environment as well as between health and environment. Some of the central issues like family planning are much debated - although less between the Mediterranean religions of revelation (12) but rather between the religious position of the holiness of life and the secular value of the well-being of a population in economic and environmental terms.

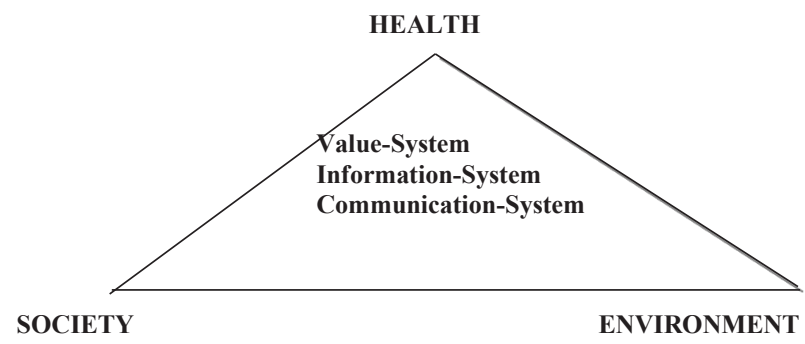

Figure 1: Elements of the "Pyramid of Development" 
The infrastructure to handle this pyramid of development has to be amended by information as a technical means and communication as a means of social organization. As much as we need an ethical orientation in terms of values, we need also information and that is scientifically validated information on the reality, the world as it is. We need an open communication system across barriers within the society, and we need fora for debate, which are not too exclusive and give a chance to all sections in society to participate and express their view. I believe the last German revolution remained without bloodshed, because very early on so-called "Runde Tische" - round tables - had been established which mitigated the confrontation and still did not allow an escape from historical forces. The pyramid of development also constitutes a pyramid of Public Health Policy as the good government has to consider its three angles altogether, if only one fails, the others suffer. Science can help to find the right balance between them as public health cannot be built on either uncritical administrative execution top-down or, likewise, uncritical action-movement bottom-up without careful analysis and monitoring. In the context of public health, this is to mean socioepidemiological research, - in its three dimensions: descriptive in terms of health statistics; analytic in terms of comparative studies; and interventive in terms of controlled trials. But it is important to realise that public health is an applied science for and among the people, it does not take place in the laboratory. Therefore, it would be a misunderstanding to withhold action until perfect proof from perfect studies is available. More relevant it is to work with the results from imperfect studies being critically aware, that they are imperfect and new results might change the course of events.

In recent years the understanding of the ONE WORLD, alive by a coherent interactive system of air, land, water, plants, animals and humans has gained affirmation and a ONE HEALTH movement is growing mainly bottom-up, a development which has recently be underlined by the Corona pandemic (13). The health of humans depend on the coherence of all natural elements (14).

\section{Health}

If we think of these three dimensions in the triangular arrangement of figure 1, health may be rightly at the top. Health has become something like a secular religion, a pursuit of happiness, especially after the allinclusive definition as physical, mental and social well-being by the World Health Organization after World War II. Health promotion has an even broader connotation as it involves general competencies and general living conditions. The Americans nicely call that "Healthism". This is no longer 
a medical domain on its own, it is an issue linked to all societal sectors, and, promptly, inter-sectoral strategies for health have been defined. But the broader the meaning of health, the less chance we have to be healthy without any impediments, i.e. to be one hundred percent healthy. There is always something left to desire! According to Karl Popper, we can falsify complete health and define what is detrimental to health, but according to him it is impossible to determine positively what health is. Therefore, health has an imprecise meaning or poetically: it always lies beyond the horizon. For that reason, we are tempted to spend all our financial resources, if necessary, and in every life there comes a moment where we would give everything to avoid serious illness and death. A often cited joke about cigarettes states "Smoke less, die healthy!". The contradiction in adjecto 'die healthy', is it a joke or could it have a serious meaning for this discourse? The approach can be passive or active to set limits to the claim for total health. The passive one is taken by most of today's governments through cost containment policies that are freezing expenses at a level of around $10 \%$ of the GNP, where we have not any argument for that quota except custom. This policy usually leaves the distribution of resources to tradition and vested interests. Rational planning is tried only occasionally and cost-benefit-analysis even more so. The active approach, on the other hand, is much more demanding: it aims at a public consensus on what we can afford, under which circumstances, and when life should be allowed to begin and to end. Then health is not everything and certainly not worth everything, but only the individual, social and material means to lead a decent life. What is adequate under these circumstances? The consensus, certainly, will be and has to be different for different societies and for different historical periods. Science can identify the facts, define the issues, and lay out scenarios for various options, but the scientist cannot make the decisions instead of the people, although very often he sees himself in this way. Decisions of that kind have to be made by society, as a whole, and its legitimate bodies.

\section{Health Sciences}

If we agree that the pyramid of development has to be built with the indispensable help of scientific reasoning, then where do we find this kind of comprehensive science? Over the last years the renaissance of the Health Sciences and the debate on a New Public Health (15) as coined by the European office of the World Health Organization - meant to be different from the classic concepts of hygiene - has led to a new model of institutionalization which is characterized by modern or New Schools of 
Public Health (NSPH). This institutional entity is not any longer directly related to the Ministry of Health as has been traditionally so, but by now is independently based as an own faculty in the setting of the university; however, contractually linked to a number of important health providers in the region with a well-defined cooperation for training and research in public health based on mutual interest.

Delineating from the aforementioned fundamentals what kind of training institutions do we need? First the NSPH should have defined - not only voluntary - links with the political and administrative system. Certainly this statement is not popular everywhere in spite of the fact that many of today's schools are state-based institutions. Nevertheless, it remains true that exerting influence in an open society is a two way business. NSPH need a direct and permanent connection to the decision making process in the administration if they want to channel their services to the relevant needs. So much of the indication for the work, the task-setting might come legitimately from the society mediated through the state and the semipublic institutions, charged with certain services like - e.g. in Germany - the independently practising physicians.

Second, in order to fulfil their duties properly and according to scientific standards, the modern NSPH requires a direct link to universities, most likely in terms of a usually postgraduate organization of training schemes leading to academic degrees, and in terms of applied research.. Funding policies are to support such cooperation. Legal provisions should facilitate exchange of academic staff with related faculties, additionally through international or national scholarship schemes. Often, the notorious antagonism between the Ministry of Science and the Ministry of Health creates unnecessary problems although a NSPH is related to both.

Third, public health is not l'art pour l'art but an applied science of preventive orientation and, the NSPHs must connect to the practice of public health and to practical intervention. They have to be institutional agents of change and not only executives. A modern School of Public Health or Health Sciences has contracted a network of institutions in the field, e.g. caring for the physically and mentally handicapped or being responsible for health reporting to the government. Partner institutions lecture at the university, and vice versa students of public health work on their theses in the institutional settings. Common research projects are pursued like, e.g. the development of a health audit for public construction works or similar activities. 
Fourth because of these multiple and potentially conflicting relationships the NSPH should have an independent institutional basis, neither an institute of the Ministry of Health exclusively, nor part of another faculty. In particular, the NSPH should cooperate closely with, but needs to be separate from, the school or faculty of medicine. Again, this is not always popular and even not the prevailing model in Europe, but at least the department of public health within a medical faculty should be as autonomous as possible. However, the public health group seems to remain in a structural minority versus the clinical disciplines, which means being at a persistent disadvantage with regard to the distribution of scarce resources between competing priorities.

The modern School of Public Health in summary is independent with strong links to universities, practice institutions, and the political administration. 'How this triangle can be organized, and what the locally appropriate balance should be is up to those who want to invest in public health' to use the words of Andrija Stampar, Chairman of the First World Health Assembly after World War II. Responsible for such decisions should be those who tackle the work: public health must be anchored in all three corners of the triangle of society, academia, and practice.

What contributions to the health of the population can we expect from such institutes and what is most necessary? In modern societies we have to cope with four main deficits regarding population health, these are:

a) The information deficit, for example how to deal with the COVID-19 pandemic.

Because of the obvious lack of sufficient and reliable information in the health sector of many countries, international as well as national initiatives have promoted the development of indicator-based comprehensive monitoring systems (mostly although not exclusively quantitative routine data) and their interpretation by experts published as reports to the general public (health reporting). Health surveillance is a prerequisite of intelligent decision making in health policy. Valid indicators are the key to meaningful analysis. Health indicators should be relevant (regarding priorities), valid (regarding determinants of health), measurable (in quantitative or qualitative terms), sensitive to change and differences, comparable (interterritorial), repeatable (as time series), affordable (in terms of relative cost), and useful (for intervention). Meeting these criteria obviously requires a permanent scientifically qualified institutional infrastructure.

b) The social deficit in terms of social, intergenerational, and cultural 
disintegration.

Today terminology has been widely accepted which uses the term "inequality" for stating differences in health status determined by social variables like educational grade, professional category and income level, sometimes added up to one integrated index of social status. By some this is called "vertical" inequality, whereas horizontal inequality may refer to various dimensions of disparities connected with sex and age or different ways of looking at a person's position in the society, e.g. marital and family status, ethnic group, whether one is a migrant or a native resident etc. Others prefer not to make such a distinction but to think instead in terms of disadvantaged or vulnerable groups such as migrating labourers, the unemployed, socially isolated elderly, and oneparent families. The value statement on inequalities most often is termed "inequity", namely whether a socially determined state of disadvantaged health is considered to be unfair and unjust because being unnecessary and avoidable. The interdisciplinary study of the determinants and possible interventions to minimize health inequities may be summarized as "Social Public Health". Social Public Health then constitutes a core sector of the New Public Health approach which has been developed throughout the nineties. Four different concepts have been discussed already in the Black Report (16) in order to explain the differences in health status by social groups: methodological artefacts, social selection, living conditions, and health behaviour. The first explanation of social gradients is deemed of little relevance: systematic methodological errors are unlikely, given the almost universal and quite uniform existence of social gradients and health inequalities. The second and third explanation are mirrored in the slogan that "Poverty drives you sick and sickness makes you poor". Together they constitute a vicious circle effective in many regions of the ('third') world especially where the population is not sufficiently covered by health insurance. As disease is more prevalent in the lower social strata, the economically disadvantaged ones may have to pay more not only in relative but even in absolute terms. Other researchers highlight the fact that at least some part of health inequalities have been shown to arise from a higher prevalence of unhealthy behaviour in lower socio-economic groups and from differences in psychosocial work environment. Disadvantaged or vulnerable groups are subpopulations being exposed to an accumulation of unfavourable determinants of health and therefore at excess risk for disease or ill health. The terminology sometimes used for underprivileged or disadvantaged groups stresses the external causation of reduced health chances; however, voluntary risk seeking behaviours may also contribute 
and should not exclude such people from supportive action. This applies even more to individuals with a limited ability to cope with strains. No systematic classification of disadvantaged groups has yet been developed, but the following for example have been suggested in various contexts: the migrating labour force, the travelling communities, the homeless, ethnic minorities, asylum seekers and refugees, elderly females living alone and in poverty, one parent families, children growing up in families on social compensation, the unemployed, and the very poor. According to Wilkinson (17) social dislocation and the disruption of social cohesion respectively may be a common mechanism of vulnerability. Furthermore many researchers hold the view that during the decade's vulnerability has gained importance vis a vis the classical vertical inequalities. On the other hand vulnerability is not necessarily static or definite but may change during a lifetime as is typically the case with regard to many states of (intermediate) poverty. The tensions originating from unacceptable differences in chances for healthy living can destroy the social web and lead to violence and war.

c) The preventive deficit in terms of lack of population strategies according to Rose and insufficient regard of environmental sustainability.

Given its great potential, the preventive sector of health services has not yet received appropriate attention. Whereas this is obvious for infectious diseases it seems to be even more relevant for chronic diseases which often start to develop early in individual lifes. Smoking, alcohol drinking and use of drugs, incorrect diet and overfeeding, too little physical exercise, insufficient hygiene and other health damaging behaviours are often responsible especially for diseases of the circulatory system and cancer. Dangerous driving, auto-aggression and unprotected sexual acts are major causes of increasing morbidity and mortality rates as well as premature death. These are mainly behaviour related risk factors, in other words they are potentially under the control of an individual. However, risk factors are based on behavioural patterns which are integrated with habitual patterns of socio-cultural lifestyles which are shaped in each case by various life situations. For this reason all preventive approaches must have behavioural and situational components. Chronic diseases, for example, are very seldom curable once they have manifested themselves but they are - at least in principle - preventable. It would be logical if some of the money allocated to treatment could be diverted to preventive activities. This could allow altering the initial conditions which contribute to the development of chronic-degenerative diseases by means of behaviouroriented prevention: promotion of health at work, housing, recreation, 
and medical services. In the future much greater consideration has to be given to the multi-dimensional interrelationship of the causes of health impairment, both in ecological research and provision of medical services. The structural problem discussed here can only be managed by means of interdisciplinary cooperation. This also applies to infra-structural and organisational problems faced by the health services.

d) The regulatory deficit in terms of an improper administrative balance between centralization and decentralization and lack of competent coordination.

Decision making in health care is organised by a regulatory framework which in most countries is characterised by a continuous shift from the old vertical model to a more horizontal one with moderating instead of a directive role of the governmental agencies. A number of decision making centres acting more or less in parallel have to be coordinated but cannot be directed. Originally organised rather in a top-down model, more and more the generation of decisions follows a bottom-up approach. This requires management which integrates several levels of a formerly hierarchical pyramid in a round table manner. A management approach of this type may be named "Horizontal Management".

As for individual therapy and even diagnosis a code of medical ethics has to be obeyed, the implementation of population-wide interventions in public health and even analytical studies have to follow ethical rules which relate predominantly to the way of how decisions in this regard are made. Five core ethical principles can be identified (Laaser et al. 2017):

Solidarity,

Equity,

Efficiency,

Respect for autonomy, and

Justice.

And in terms of operational ethics:

Serving the common public good

Stewardship, and

Keeping promises. 
The public health professional having encompassed successfully education in a School or Department of Public Health as outlined may be described according to the following competency profile:

Follows a professional code of ethics

Accepts accountability towards society

Work for evidence based action

Aims at structural and stable solutions

Understands the global context of public health

Understands the multifactorial determination of public health

Be prepared for transnational management

Be qualified for transcultural, interdisciplinary and multi-professional cooperation

Knows assessment technologies

Have acquired consulting competencies

Be trained for leadership in services

Be competent for research and development in the service environment

Be knowledgeable in foreign languages, the use of internet, presentation techniques, moderation skills, conflict management, and teamwork interaction.

It will be along and never ending way to achieve this with the limited resources available. However, training for research and serving the health of populations is a mission well worth the effort.

It is obvious that no single science can deliver all solutions required, that is why public health is an interdisciplinary and multi professional science. Which disciplines constitute the canon? All disciplines which contribute to the public health of populations can be called - with regard to that specific contribution - public health sciences, whether they come from the medical, biological or natural sciences or from the social and management sciences. Fields of application are for example rehabilitation or nursing or what we call in Germany 'social psychiatry'. They increasingly develop a tendency 
to form their own bundles of related sciences like rehabilitation sciences or nursing sciences. On the other hand, there are basic, instrumental disciplines related to the very triangle of public health mentioned above.

Table 1: The Basic Public Health Sciences

\begin{tabular}{ll}
\hline Scientific Foundation & Epidemiology and Biostatistics(Academia) \\
\hline Preventive Orientation & $\begin{array}{l}\text { Health Protection and Health } \\
\text { Promotion(Practice) }\end{array}$
\end{tabular}

\begin{tabular}{ll}
\hline Societal Dimension & HealthPolicyandManagement(Organisation) \\
\hline Environmental Protection & One Health \\
\hline
\end{tabular}

These subjects are essential for policy making and efficient health planning:

- establish epidemiologically priorities in terms of which health problems are most important, and which groups are most vulnerable;

- define exposures and environmentally or occupationally determined health problems and to design and try out interventions;

- health policy and management is needed to translate empirical findings into health policy, as well as, to find proper ways to implement the latter;

- a new modern framework is provided by the One Health concept.

Public health training requires public health research. Here we should stick to Humboldt's ideal of 'Lehre und Forschung'. Teaching and research are interlinked. Therefore, to be responsible for training also implies to be charged with research or more precisely training for research. However, I would give it a special term as 'applied' research, i.e. research oriented towards practical application or in another wording 'interventive research', namely how and to what effect can we improve the health of populations?

An account of hypotheses to explain the growing differences in life expectancy between East and West Germany since the 1970s, more than two years in favour of the West by the year of change 1989, should help to illustrate the extreme importance of a public health research agenda: 
Hypotheses Raised to Explain Differences in Life Expectancy between Germany East and West:

1) The organization of health care (centralization, institutionalization)

2) Resources available for allocation

3) The provision of high-tech medicine

4) Degree of public information and participation (e.g. self-help-groups)

5) Quality of nutrition

6) Consumption of tobacco and alcohol

7) Environmental pollution

8) (Selective) East-West migration.

To intensify collegial contacts is a must in the field of public health - in Corona-times specifically by digital communication - as demonstrated by the complexity of these issues. When we talk about solving problems of this kind, generally the basic methods are the same, for methodologies are based on scientific knowledge and science does not differ with changing geographical location. Hence for the development in health, it is vital to learn from each other in the belief that health and knowledge knows no barriers. The Holy Prophet of the Muslims (PBUH) said that "seek knowledge even if you have to travel to China for it." The matter of concern here is very obviously learning, and not by whom or using whose knowledge. This statement may also imply that knowledge from, obviously metaphorically speaking, China might be applicable in Saudi Arabia. And it may imply that we are not only rational beings as going to China at least at the times of the prophet certainly was not the most rational thing to do. A citation from Le Petit Prince de Antoine de Saint-Exupéry (18) explains this in more detail:

"Si je vous ai raconté ces détails sur l'astéroide B 612 et si je vous ai confié son numéro, c'ést à cause des grandes personnes. Les grandes personnes aiment les chiffres. Quand vous leur parlez d'un nouvel ami, elles ne vous questionnent jamais sur l'essentiel. Elles ne vous disent jamais:"Quel est le son de sa voix? Quels sont les jeux qu'il préfère? Est-ce qu'il collectionne les papillons ?" Elles vous demandent: "Quel àge a-t-il ? Combien a-t-il des frères? Combien pèse-t-il ? Combien gagne son père?" Alors seulement elles croient le connaitre. Si vous dites aux 
grandes personnes: "J'ai vu une belle maison en briques roses, avec des géraniums aux fenètres et des colombes sur le toit..." elles ne parviennent pas à s'imaginer cette maison. Il faut leur dire: "J'ai vu une maison de cent mille francs." Alors elles s'écrient: "Comme c'est joli!"

\section{References:}

1. 1. Birkeland H. The interpretation of Surah 107. Studia Islamica 1958; 9: 13-29.

2. United Nations 2000. https://www.un.org/millenniumgoals/bkgd. shtml

3. United Nations 2015 (updated). file:///C:/Users/ULRICH 1/AppData/ Local/Temp $/ 21252030 \% 20$ Agenda $\% 20$ for $\% 20$ Sustainable $\% 20$ Development\%20web.pdf

4. Laaser U. German Health Policies in the Years of Change. In: Stock C, Laaser U (eds.): Public Health in Eastern Europe. Z. Gesundheitswissenschaften 1994; suppl 1: 41-47

5. Laaser U, Schröder-Bäck P, Eliakimu E, Czabanowska K and ThinkTank for Sustainable Health \& Well-being (GHW-2030) TOHG. A code of ethical conduct for the public health profession. South Eastern European Journal of Public Health (SEEJPH) 2017. doi: 10.4119/ seejph-1863.

6. Laaser U, de Leeuw E, Stock C.(eds.): Scientific Foundations for a Public Health Policy in Europe. Juventa-Verlag, Weinheim 1995.

7. Rose G.: Relative Merits of Intervening on Whole Populations Versus High Risk Individuals Only. In: Lauer R.M., R.B. Shekelle (eds.): Childhood Prevention of Atherosclerosis and Hypertension. Raven, New York 1980.

8. The Intersalt Cooperative Research Group. Sodium, potassium, bodymass, alcohol and blood pressure: The INTERSALT Study. Hypertension 1988; 6 suppl. 4: S.584-586.

9. Rose G, Day S. The population mean predicts the number of deviant individuals. BMJ 1990; 301: 1031-1034.

10. Laaser U. (im Auftrag des Vorstands der Deutschen Gesellschaft für 
Sozialmedizin und Prävention): Laudatio Prof. Geoffrey Arthur Rose, CBE. Öff. Gesundh. Wes. 1991; 53: 719-724.

11. Stein H. The Maastricht Treaty 1992: Taking stock of the past and looking at future perspectives. South Eastern European Journal of Public Health (SEEJPH) 2015. doi: 10.4119/seejph-1803.

12. McIntosh CA, Finkle JL. The Cairo Conference on Population and Development: A New Paradigm? Population and Development Review 1995; 21: 223-260. DOI: 10.2307/2137493. Available at: https://www. jstor.org/stable/2137493.

13. Ivanovic et al. (2020) "Serbian Citizens' Opinion on the COVID-19 Ivanovic $M$ et al. Serbian Citizens' Opinion on the COVID-19 Epidemic. South Eastern European Journal of Public Health (SEEJPH), 2020. doi: 10.4119/seejph-3459.

14. One Health Commission. Available at:https://drive.google.com/ drive/u/0/folders/1G1aV5i3UkuvkDz4ckUmSkxKEv1PHYjmy. Visited 7 August 2020

15. Laaser U. The institutionalization of public health training and the health sciences. Public Health Reviews 2002; 30: 71-95.

16. Department of Health and Social Security (DHSS). Inequalities in health: Report of a research working group (the Black Report). London, 1980

17. Wilkinson R. The epidemiological transition from material scarcity to social disadvantage. Daedalus 1994; 123: 61-77.

18. Saint-Exupéry, A. de. Le Petit Prince. Gallimard, Paris 1946. 